\title{
اللغة العربية الفصحى المعاصرة وتعليمها
}

Farid Permana

STIQ Amuntai, Kalimantan Selatan, Indonesia

Email: faried88@gmail.com

\section{مستخلص البحث}

اللغة العببية الفصيى من اللغة الأصلية الرسمية التي جاء بها القرأن الكريم والأحاديث النبوية. وهذه اللغتة ذات مستويات في استخدامها وتلعب دورا هاما في انتشار العلوم والفن والتكنولوجيا الحسليثة. وتعليم هنه اللغتة من الأمور التي لايتركها الملدارس في أنحاء العاله. ومن بين ذلك، هناك تواجه اللغتة العبربية الفصحى هجمة شسرة من قبل أعدائها متهمين إياها بالعجز، والتقصير عن الته مواكبة متطلبات الحياة المعاصرة، هذا الواقع يفرض على أبناء الأمة العربية إثبات خصائصها ووظائفها في المجالات كافة، فهي لهم تعجز عن استيعاب العلوم

$$
\text { المحسدثة، لأنها ذات قدرة توليدية. }
$$

\section{الكلمات الأساسية: اللغة العربية، تعليم العربية الفصعى.}

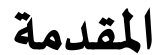

إن اللغـة العربيـة ألـة فاعلـة فى عمليـة التطـور الإنسـاني وإن اللغـة تتطور بمظـاهر الإعـراب والنحت وهمـا سـمتان خاصـتان فى اللغـة العربيـة التى هي لغـة القـرآن الكـريهم والعبـادات والمعـاملات والآداب والفنـون، ومـن هنـا يمكـن دراسـة اللغـة باعتبارهـا علمـا لها خصيائصيه كعـائلات لغويـة او اسـرة متكاملة تشـمل علم اللغـة العـام وعلـم اللغــة الإجتـمـاعي وعلـم اللغــة التـاريخي وعلـم اللغــة الوصـفى، ويوجد بينها صلة وتشاباء'

' عبد الجني، نقه اللغة وعلم اللغة نصوص الدراسات، (القهرة: دار المعرفة: 990 1) ص. 
إن اللغـة العربيـة اليـوم تشهـد تحـديات عربيـة وعالميـة في العصر الحـالي مـن خصـومها، بسـبب الظـروف الراهنـة التي تحـيط بهـا، منهـا إطـلاق الـدعوات إلى تهميشها، أو تغييير سـماتها، أو الانتقاص من وظيفتها، هذه الظروف تفرض علينا

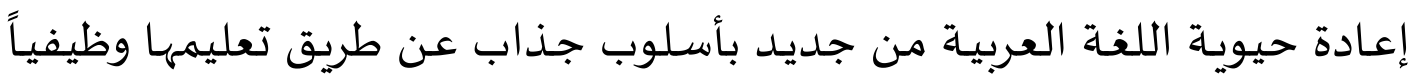
في ميادين العلم والمعرفة، وخلق ذائقة فنية لدى المتعلمين الصغار؛ للإقبال على تعلـم اللغــة العربيـة مـن خـلال الإحســاس بقيمتهـا، وكنوزهـا الثمينــة، بحيـث يتمكنون من استعمالها في المواقف اللغوية كافة .

كـذلك تواجــا اللفـة العربيـة هجمـة شرسـة مـن قبـل أعـدائها متهمـين إياهـا بالعجز، والتقصير عن مواكبة متطلبات الحياة المعاصرة، هذا الواقع يفرض على أبناء الأمة العربية إثبات خصيائصها ووظائفها في المجالات كافة، فهي لم تعجزعن من اسـتيعاب العلوم المحدثة، لأنها ذات قـدرة توليديـة ـ وهـذا يـدعونا إلى نشـر تعليم اللغة العربية في المراكز الثقافية، لأها مركز حضياري للثقافة اللغوية المجتمعياة. من هنـا يـحاول البحثث إلقـاء الضـوء على الآليـة التي تسههم في ازدهـار اللغـة العربيـة الفصــى والارتقــاء بهـا عـن طريسق تخــديم اللغــة العربيـة في المـدارس والمعاهد والجامعـات، واعتماد اللغـة العربيـة الفصيتى أسـاس الخطاب في قاعات الدروس، والمؤتمرات، وتعريب التعليم الجـامعي، وسـن قوانين للحـدّ من استعمال اللغـة العاميـة في فضيائيات الإعلام المرئيـة والمسـموعاة، باعتبـار أن وسـائل الإعلام هي المسؤولة بالدرجة الأولى عن تفشي اللغة العامياة، وميل المتعلمين إلى التحدث

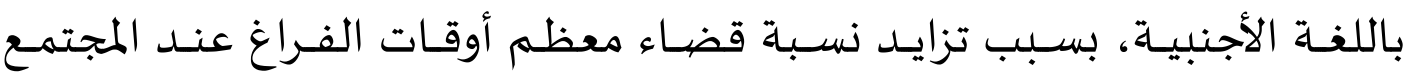
الأسـري أمام التلفاز بالقياس إلى ما يحصله كلّ متعلم من رصيد لغوي في المجتمع المدرسي أو في المعاهد والجامعات. 
إزداد ولا يزال يزداد إقبال الدارسين والمهتمين والمحبين للغـة العربية، سـواء فى المسـتوى الإقليهي أو فى المسـتوى العـالمي، وهـذا يحثنـا على حفـاظ هـذه اللغنة العربية الفصيحة في هذا العصر الحاضر.

وسوف تتحدث هذه المقالة عن اللغة العربية الفصدى المعاصرة وما يتعلق بتعليمها في جامعة علوم القرآن بآمونتاي كليمانتان الجنوبية. وهذا البحث من النـوع الوصـفي التحليلي بالمـدخل الكيفي. وكانـت البيانـات محصيـلة مـن خـلال الملاحظة الميدانية.

\section{أ. اللغة العربية الفصدى المعاصرة}

اللغـة العربيـة الفصـحى هي لغـة القـرآن وأصـل هـذه اللغـة على وجـــ الدقـة محل خلاف بين البـاحثين، في العصر الحـديث، شـاع استخدامها بين المتحـدثين بالعربيـة بعد انتشـاروسـائل الإعلام الحديثة مثل الإذاعـة والتلفزة والصحافة، وقد تأثرت أيضـا باللهجـات العربيـة المتعددة والأسـاليب والتركيبات التي طورها الأدب العربي الحـديث من ناحيـة وباللغـات الأوربيـة، وعلى رأسها الإنجليزيـة والفرنسية، من ناحية أخرى؟

فـإن اللغـة الإنسـانية كائن حي - كمـا قـال جرجى زيـدان - مـا زالت ولا

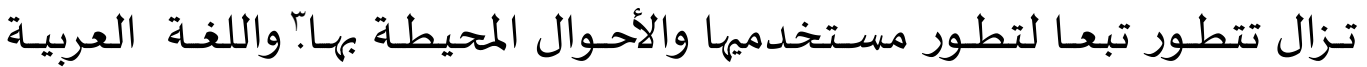
كلغـات أخرى لا تقفـ عند حـد، بـل تسـير مع الركب جنبـا إلى جنب مع اللغـات

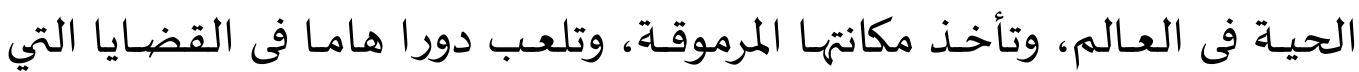
تمس الحياة الإنسـانية فى الكوكب الأرضي، حتى ارتقت وصـارت إحـدى اللغـات

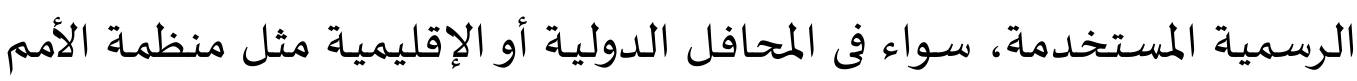
المتحـدة والمؤسسـات التابعـة لها ودول عـدم الانحيازوالمؤتمر الإسـلامي وجمعيـة الدول المنتججة للبترول وغير ذلك. 
وفى الواقع أن اللغة العربية - كما رأى الدكتور رشـدي أحمد طعيمة -

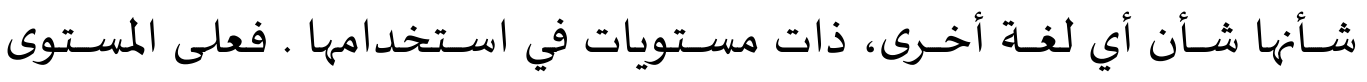

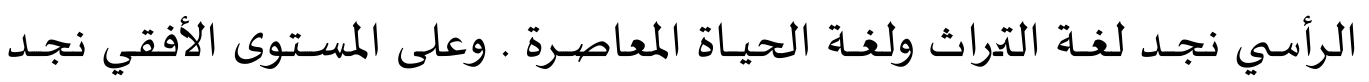

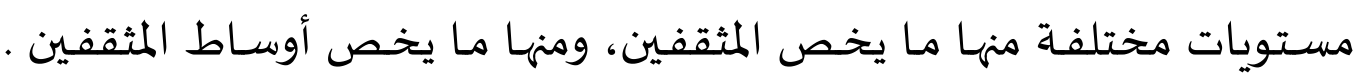

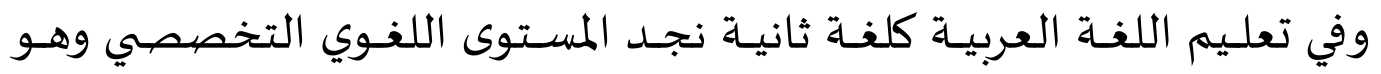

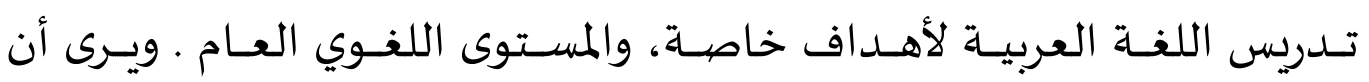

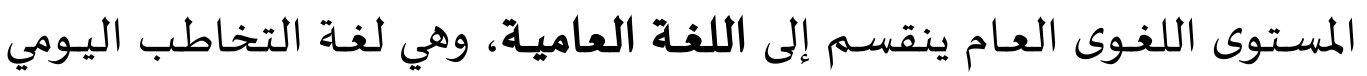

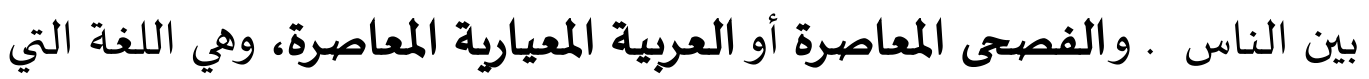
تكتب بها الصحف اليومية والكتب والتقارير والخطابات، وتلقى بها الأحاديث

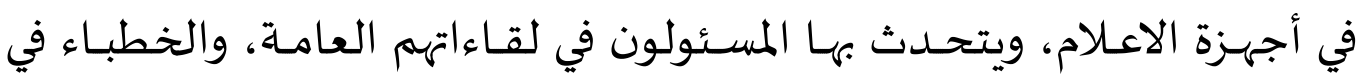

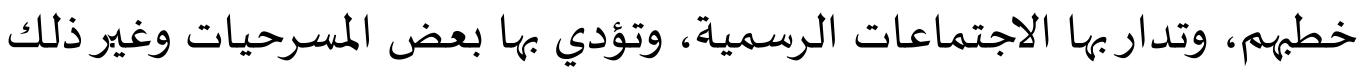

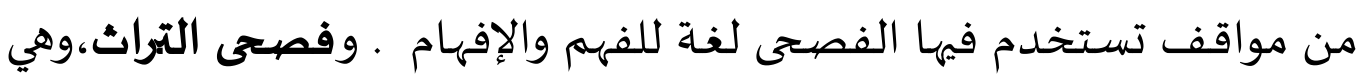

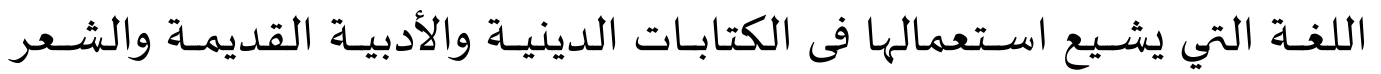

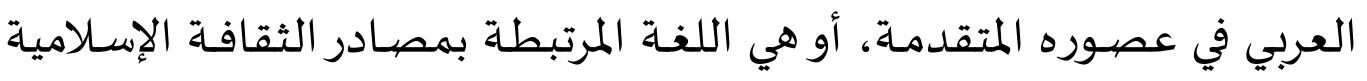

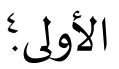

فاللغة العربية الفصحى هي اللغة العربية الرسمية التي ينص عليها أيضاً

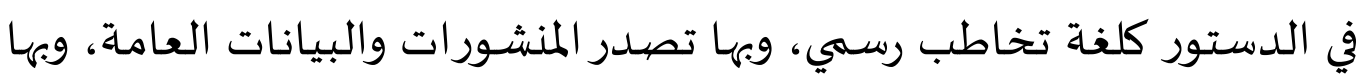

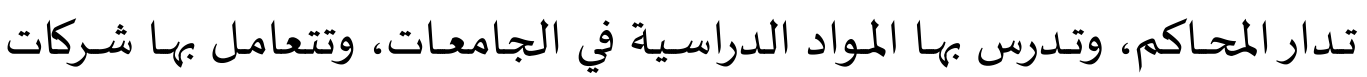

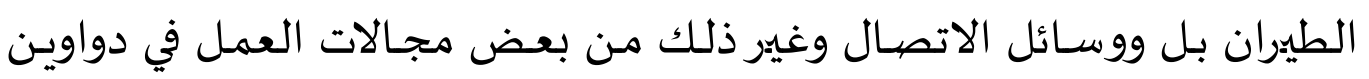

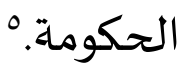

" رشدي أحمد طعيمة، تعليم العربية لغير الناطقين هما(الرباط : المنظمة الإسلامية للتربية والعلوم والثقافة

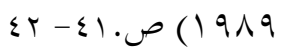

$$
\begin{aligned}
& \text { " مرجع سابق، ص. }
\end{aligned}
$$


ومـن المهم أن يلاحظظ هنـا أن اللفــة العربيـة الفصيحى المعاصـرة لا يقصيد معناهـا الواسـع الـذى يضـم كل مسـتويات اللغــة العربيـة وإنمـا المقصـود بهـا المستوى الفصيح من اللغة، ووصفها بالمعاصرة للدقة فى التعبير عن اللغة التى تعاصرنا وتعيش على ألسنتنا، فالوصف" معاصرة "مأخوذ من: عاصر فلانًا، أى عاش معاه في عصر واحد?

والعربيـة المعاصيرة التي هي لغـة الكتابـة والأدب والصسحافة والاسـتعمال الرسسي في أقطارنا العربية هي الصهورة الجديدة التي أصابها التطورِّو بجانب ذلك يطلق على العربيـة المعاصـرة مصيطلحات عديـدة بين البـاحثين، أشهرها

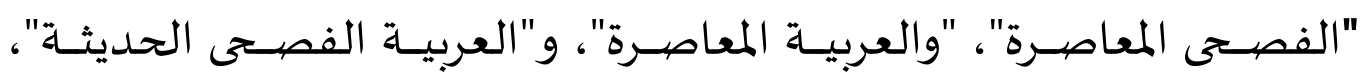

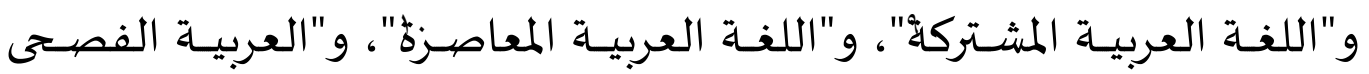
المعاصـرة"، وغير ذلك من المصـطلحات، واختيارنـا مصطلح العربيـة المعاصـرة؛

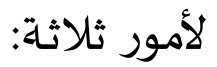

إيثارًا للاختصـار، وهـو من سـنن العربيـة، حين يـلـل الحـال أو الموقف

$$
\text { ب) تحلى الكلمةة؛ فإنها تحذف للعلم بها. }
$$

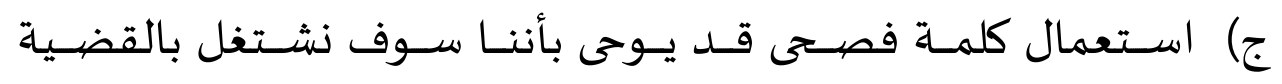
القديمة الجديدة: قضية الفصحى والعامية.

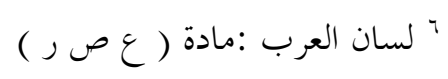

× عمدد عبد الفتاح العمراوي، تطور اللغة العربية المعاصرة بين ضوابط القدماء وجهود المحدثين (عمان: دون

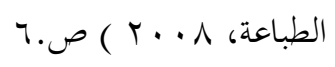

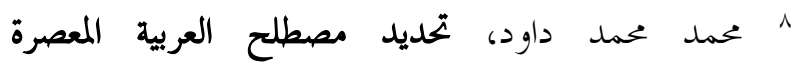
(www.mohameddawood.com/view.aspx?ID=4308\&topic=)

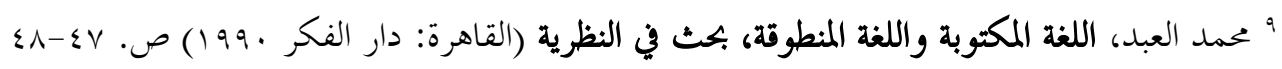

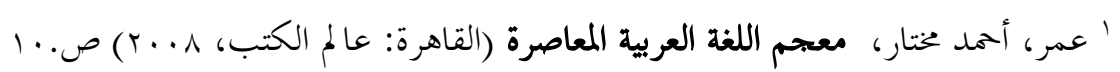




\section{ب.خصائص العربية الفصحى}

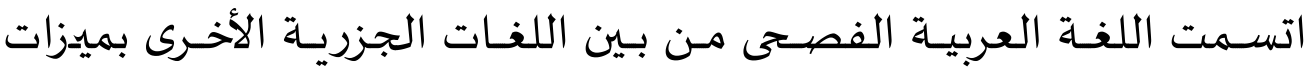

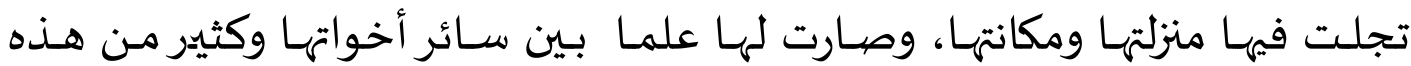

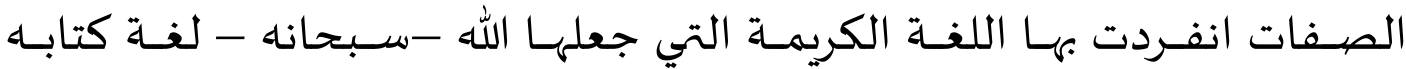
الكـريم، وتتجلى هـذه الخصيائص في ظـاهرة الاعراب،ومناسـبة الحـروف لمعانيها

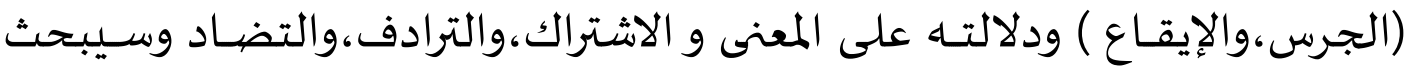

$$
\begin{aligned}
& \text { عن أربعة منها فقط وأولها الاعراب : } \\
& \text { أ-الاعراب وأصيالته : }
\end{aligned}
$$

يعد الاعراب من اظهروأقوى ميزات وخصائص العربية، إذ إن هذه الظاهرة قـد فقـدت في بقيـة اللغـات الجزريـة كلهـا تقريبـا، فتجـردت منهـا الآراميـة ولهجتهـا

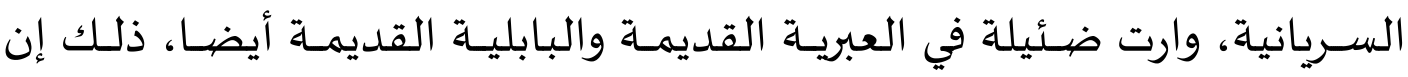
البابليـة بـدأت بثلاث حركات اختصـرت بعـد ذلك إلى اثنين، على حين احتفظت

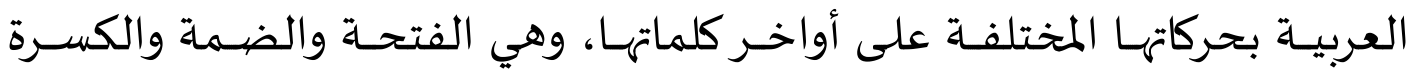

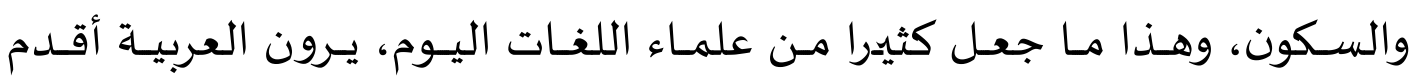
اللغات الجزرية، وذلك لبقاء عنصر الاعراب فهها، الذي يعبر في العربية عن مراد

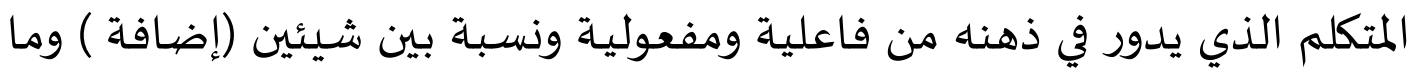

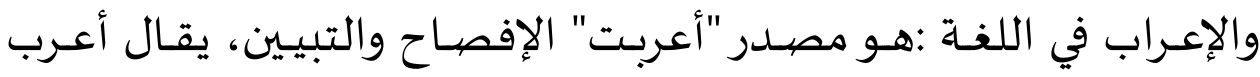

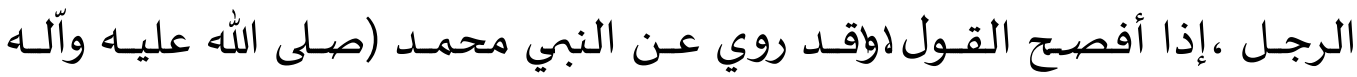

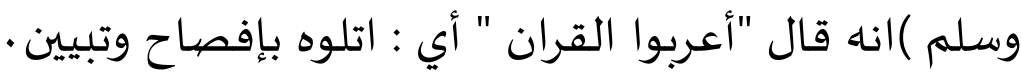

' أنظر أيضاً إلى يعقوب، إميل بديع, موسوعة علوم اللغة العربية (بيروت: دار الكتب العلمية، ج...r) ص. 
إما في الاصطلاح فقد أعطي الإعراب تعريفات عديدة منها : ( اثر ظاهره

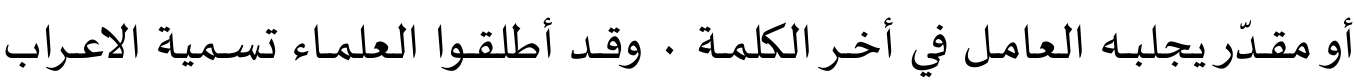

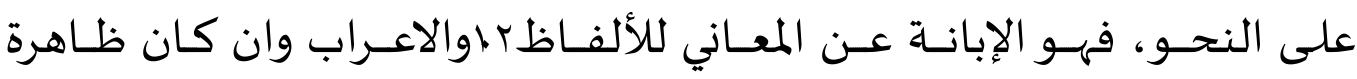

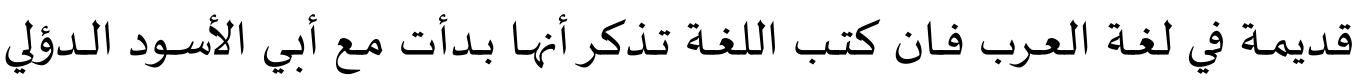

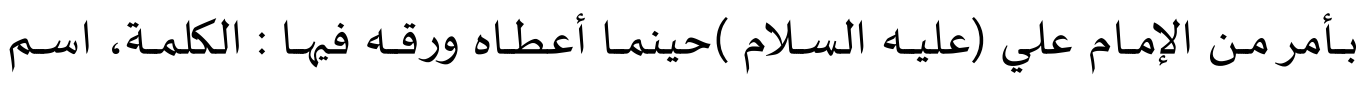

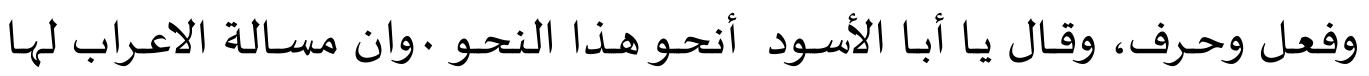

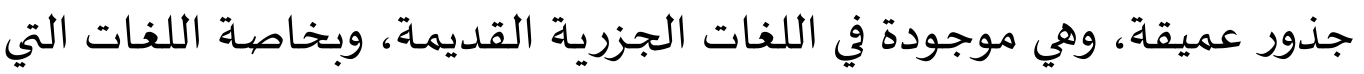

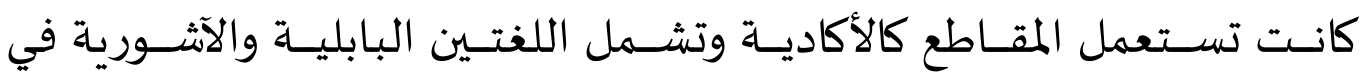
عصورها القديمة، وكانت العبرية و الأرمية والحبشية تعرف الاعراب.

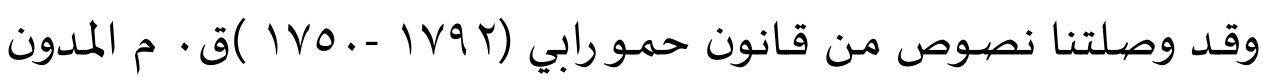

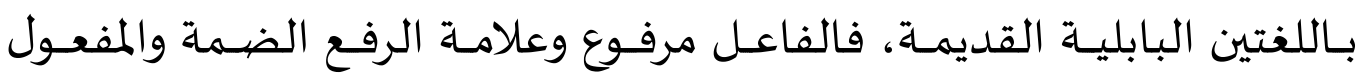

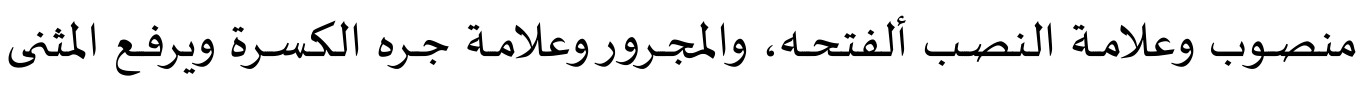

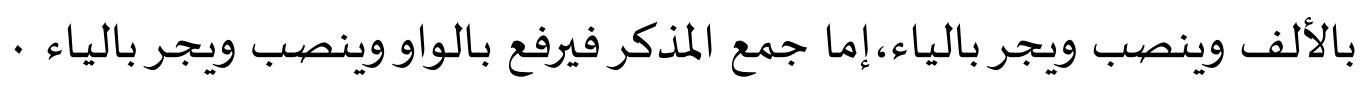

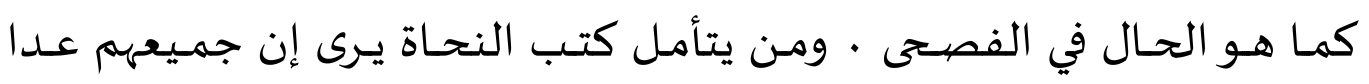

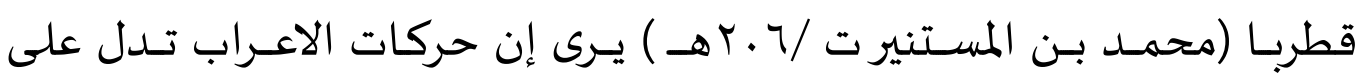

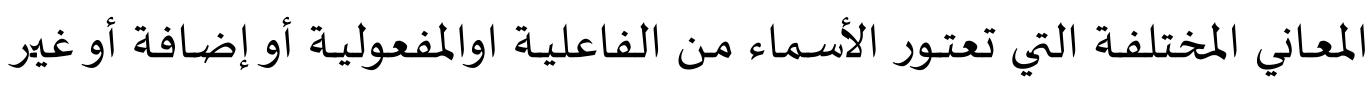

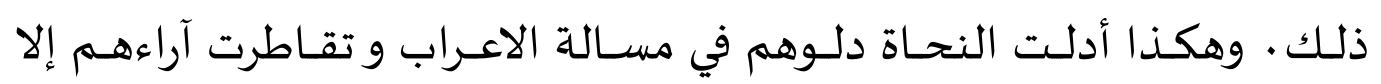

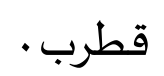

إن الاعراب كان عاملا مهما في تكوين الجملة بل كان عاملا مساعدا في إنشاء

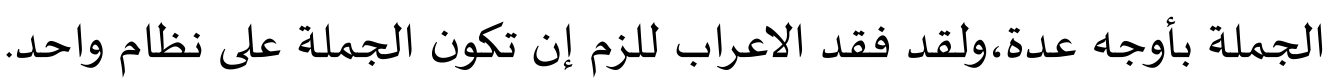

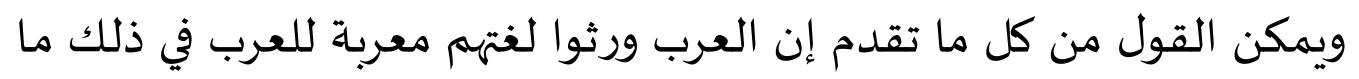
ليس لغيرهم يفرقون بالحركات وغيرها بالمعاني.

$$
\text { ' (ابن جني، أبو الفتح عثمان، الخصائص (بيروت: دار الكتب العربي) ص.0r }
$$


اللفظ المشـترك هـو اللفظ الدال على معنيـين مختلفين فأكثر دلالة على

$$
\text { السواء عند أهل تلك اللغةّا }
$$

ظن أبو علي الفارسي وذكر بان :اتفاق اللفظين واختلاف المعنيين،ينبغي أن لايكون قصدا في الوضع ولا أصلا،ولكناه من لغات تداخلت، أو إن تكون كل لفظة تسـتعمل بمعنى ثم تسـتعار لشيء، فتكثر وتغلب، فتصيـر بمنزلة الأصيل وعلى هـذا

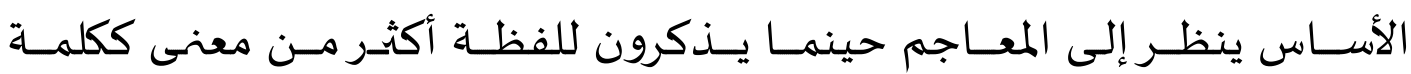
(العجوز)الـذي أورد لها صـاحب القـاموس أكثثر مـن سـبعين معنى وهي (الإبـرة، الأرض،الأرنب،والأسى،والألف من كل شيء، والبحر، والبطل، البقرة، والتاجر،و الفرس.

ويمكـن القـول إن المشـترك اللفظي،هنـاك مـن ينكـره وهنـاك مـن يقـره في

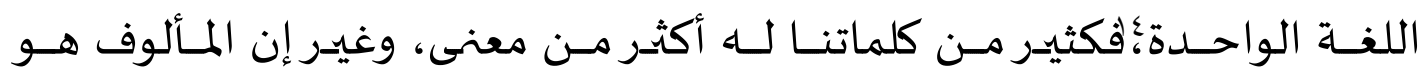
اسـتعمال معنى واحسد فقـط، مـن هـذه المعـاني في السـيـاق المعـين فالفعـل (أدرك) مثلا إذا انتزع نمن مكانه في النظم يصبح غامضيا غير محدد المعنى ومعنـاه لحق بـاه أو عاصره، أو رأى، أو بلغ الحلم، انه التركيب الحقيقي المنطوق بالفعل،هو وحده الذي يمكنـا أن يجيب عن هذا السـؤال، فإذا تصيادف أن اتفقت كلمتـان أو أكثير في أصــواتها اتفاقـا تامـا، فـان مثـل هـذه الكلمـات لا يكـون لهـا معنى البتـاة، دون

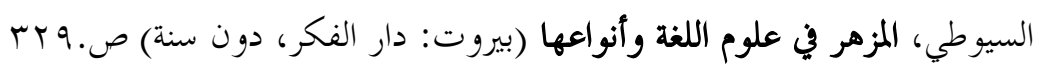

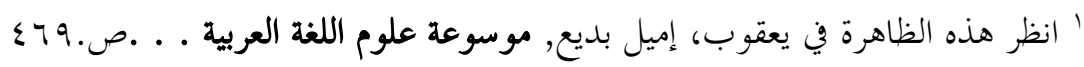


السياق الذي تقع فيـه ـ وأيضـاً أن الاشـتراك اللفظي، ظـاهرة موجـودة في معظم

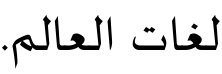

\section{ج. اللغة العربية الفصيى وأساليها}

فقد بين الواحد أن الأساليب العربية تتنوع بحسب السماتيات الغالبة عليه،

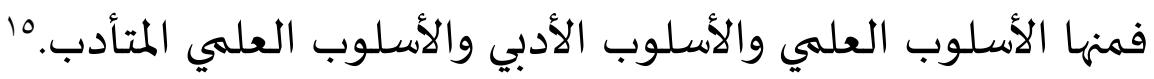

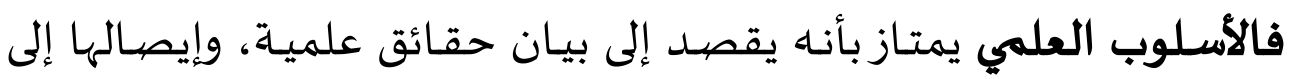

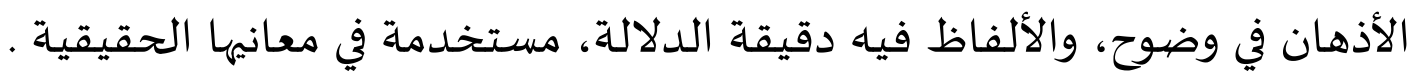

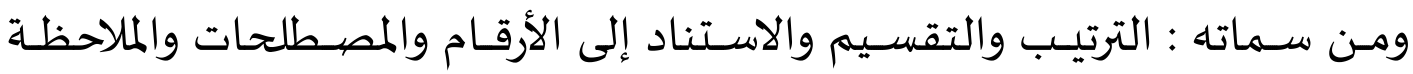

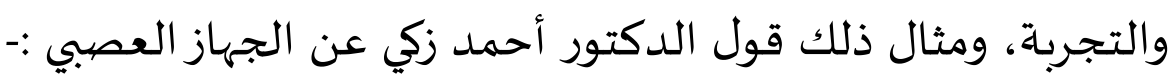

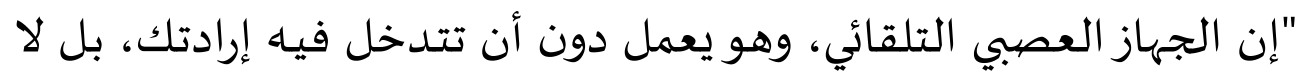

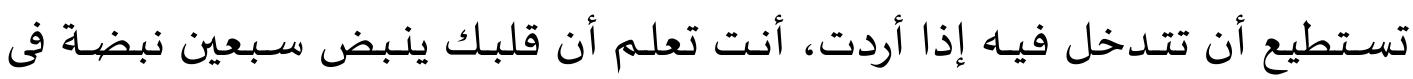

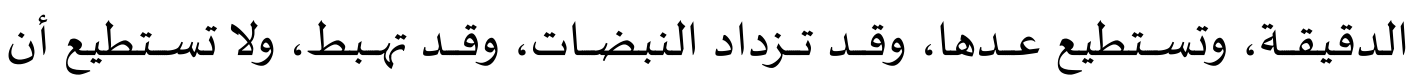
تزيدها أوتنقصَها ..." .

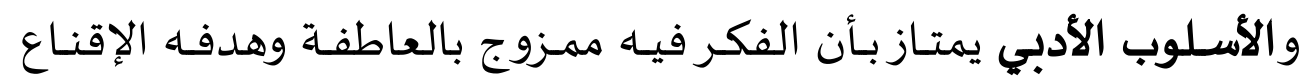

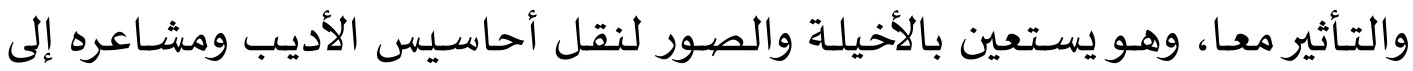

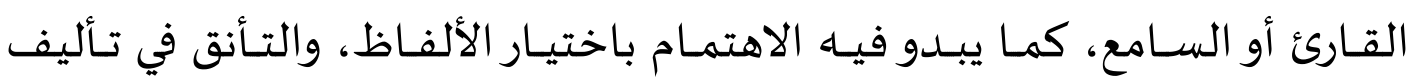

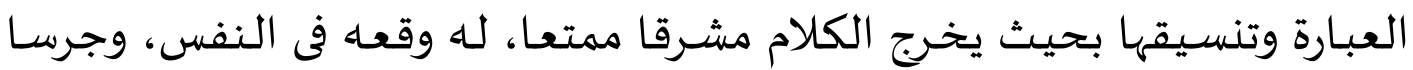

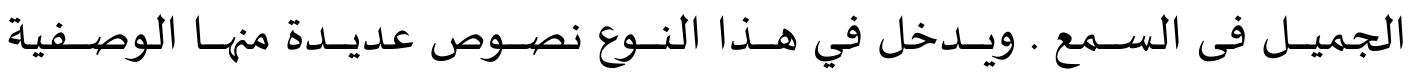

' الواحد ، السيد على عبد . دون تاريخ ـ المعلم فن اللغة العربية (القاهرة : المؤسسة العربية الحديثة، 9/9 (1) 


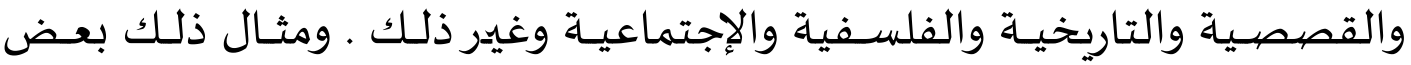
المقتطفات من خطاب مولر إلى استيفن يعبر عن أحاسيسـه :-" أكتب إليك كتابي

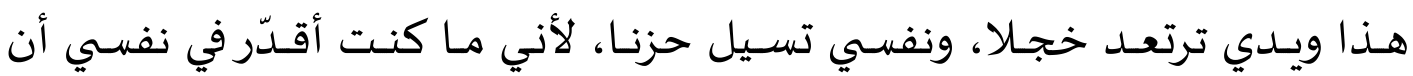
تسـتمر بي سـاعـة مـن سـاعات حيـاتي أرى نفسي فيها مضـطرا أن أقـول لصسديقي الذي أجله وأعظماه وأنزله من نفسي خير منزلة ... " . والأسـلوب العلهي المتـأدب يغلب عليـه الطـابع العلمي، ولكنـه يأخــ مـن سـمات الأسـلوب الأدبـي بنصـيب، لأنــه ينقـل الحقــائق ممتعــة مـؤثرة مـع دقتهـا ووضوحها.ومثاله ما يقال عن السلام :-" وحين يقال : إن السالام ليس فطريا، وإن جذوره تمتـد إلى الجانب الحيـواني فى الإنسـان، يسـاق هذا القول في حرص، ومع

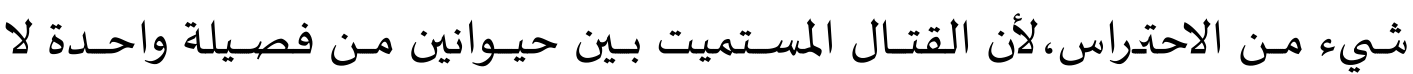
يحدث إلا نادرا، كما أن القتل الجماعي على نطاق واسع يكاد لا يحدث بينهما ... "

وأضياف مؤلفوا " الدليل الحديث في الترجمة " نوعين آخرين من الأسـاليب العربية وهما : الأسلوب الصحفي والأسلوب التجاري . ويقولون إن للصحافة لغة خاصــة تختلـف عـن غيرهـا ـ فالصسحافة تعـالج موضـوعات مختلفـة مـن سياسـة واجتماعيـة واقتصـادية وأخباريسة وغيرهـا ـ ونظـرا لأن القـارئ عنـدما يطـالع خبيرا سياسيا في صحيفة، يوجاه اهتمامه في الدرجة الأولى إلى مادة الخببر دون النظر إلى العبارة التي صيخ فيها، لذذا فقـد تطورت لغـة الصصحافة بحيـث أصبـحت تهتم في

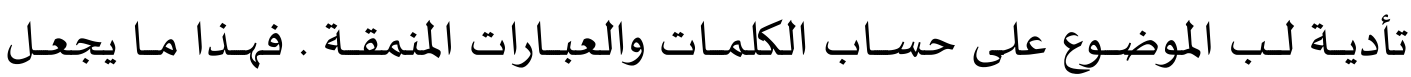
للصححافة لغة خاصية .

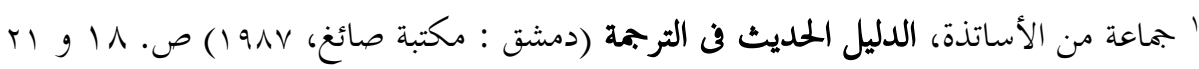


وأما الأسلوب التجاري فله لغتاه واصطلاحاتاه الخاصية باه، وغالبا ما تكون العبـارات مختصـرة مفيـدة ، وخاصــة فى المعــاملات و المراسـلات التجاريــة دون اللجوء إلى العبارات المنمقة، والتعليلات الطويلة الغامضية .

وممـا تقدم عـن اللغـة الفصـحى المعاصـرة وما تعلق بها، صيدر السـؤال، أن هذه اللغة واجهت خصومها أي العامية أو الدراجة، كيف نفرق بينهما؟

\section{د. الفرق بين اللغة العربية الفصهى المعاصرة و العامية}

وإذ عـدنا إلى التفريقـة بـين اللغــة المشـتركة واللغــة المعياريـة (وكلتاهمـا تشترك في اشتمالها على صورة مكتوبة وصيورة منطوقة) لاحظنا ما يلي: أ) أن اللغة المعيارية لغة مشترك بالضرورة

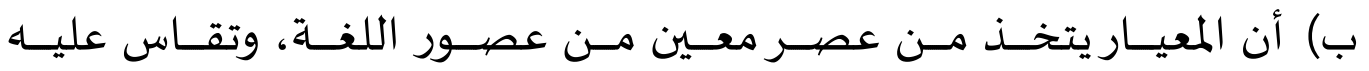
الاستعمالات اللغوية في عصور الأخرى تالية.

ج) أن اللغة المعيارية ترتبط ارتباطاً أسـاسياً بالجانب القواعدي للغة. د) أن اللغة المشتركة تمتلك أكثر من مستوي لغوي، وتتفاوت هذه المستويات فيما بينها : اقترابا وابتعادا من المعيار.

ه) أنـا في إطلار اللغـة العربيـة، بنـيت العريـة المعياريـة (أو عربيـة النحـاة ) على ألى

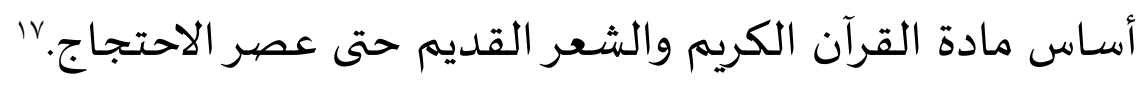

يشير شانك، شونتال إلى أن الاصطلاحي اللغة الدراجة (العامية) ولغة الحياة اليومية يدخلان غلبا في علاقة

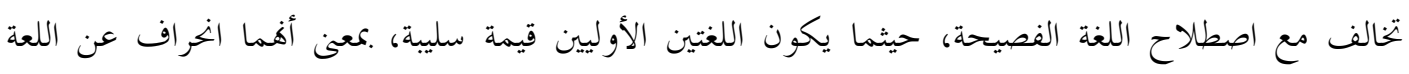


فمن التفريقة السـابقة يمكن القول أن اللغة الفصحى المعاصرة هي لغة مشترك التي ترتبط بالقواعد اللغوية نحويا وصرفيا على أساس القرآن والشعر القـديم، ويمكـن اسـتخدامها في الكتابــة والنطـق. و تتغيـر بمـرور الـزمن ومـا

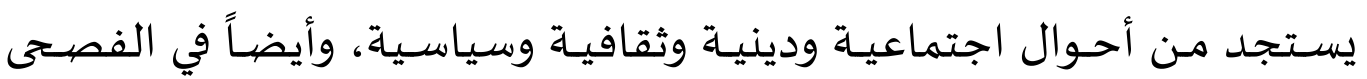
المعاصـرة تغيرت معاني ألفاظ كثيرة عما سـجلته المعاجم القديمـة إما بتعميم

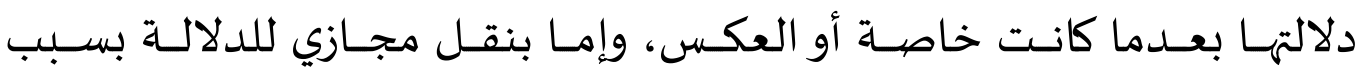
المجاورة أو السببية أو اعتبار ما سيكون، أو غيرها من طرق النقل.

\section{هـ من أمثلة اللغة العربية الفصحى المعاصرة}

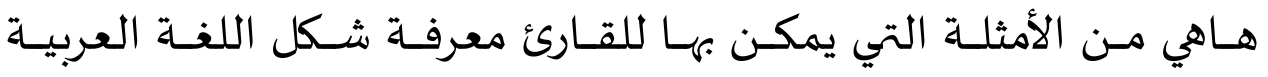

الفصحى المعاصرة، 11

\section{المثال الأول: نص الخبر}

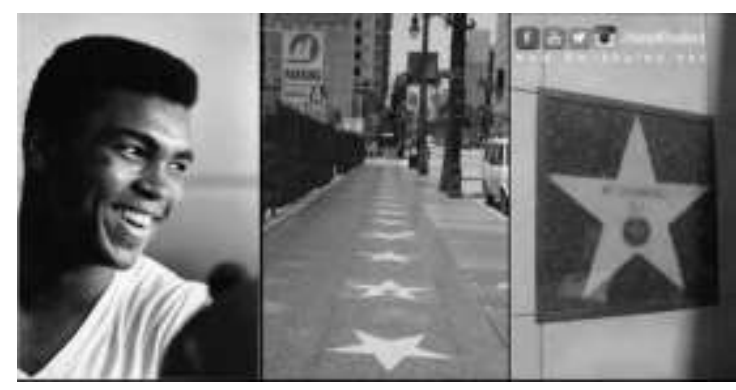

"نجم الملاكمة المسلم ( محمد على كلاى ) عندما أخبروه

أههم قرروا وضع إسماه ضمن أسماء النجوم المشهورة ف ممشى المشاهير بـ هوليوود رفض حتى لا يداس على إسم

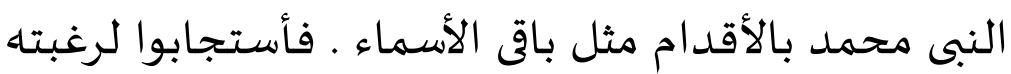

الفصيحة. انظر إلى محمد العبد، اللغة المكتوبة واللغة المنطوقة، بحث في النظرية (القاهرة: دار الفكر .991) ص. $\varepsilon \wedge-\varepsilon \vee$

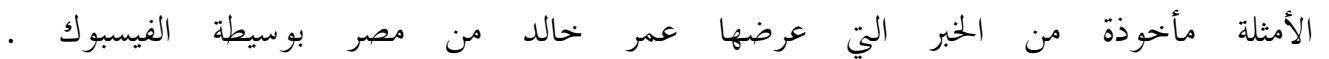
www.facebook.com/AmrKhaled/photos/a.122134131164.102452.102289881164/101532653489661 


$$
\begin{aligned}
& \text { وكان إسماه هو الإسم الوحيد الذى تم تعليقه على } \\
& \text { الحائط ! } \\
& \text { صلى الله على محمد صلى الله علياه وسلم" } \\
& \text { يمكن ترجمتها إلى اللغة الإندونيسية ما يلي: }
\end{aligned}
$$

"Muhammad Ali, bintang tinju muslim itu, ketika namanya akan diabadikan bersama nama para tokoh terkenal di "trotoar para pesohor" di Hollywood, ia menolak dengan tegas, karena itu sama saja dengan membiarkan nama Nabi Muhammad diinjak kaki seperti nama-nama pesohor yg lain. Sikap tegasnya itu dihargai. Akhirnya, namanya

\begin{tabular}{|c|c|}
\hline 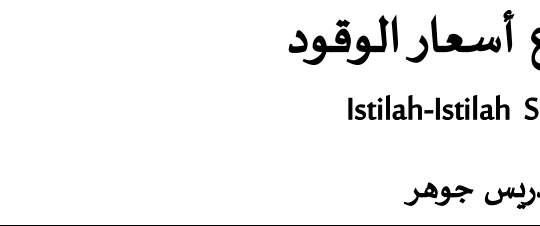 & 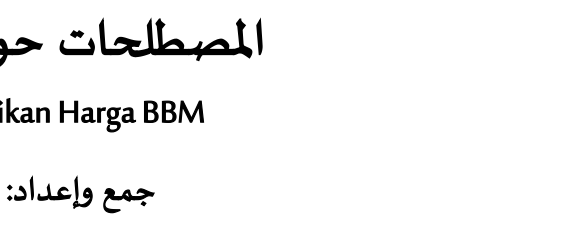 \\
\hline الوقود & BBM \\
\hline الوقود الملدعوم & Kenaikan Harga BBM \\
\hline زيادة أسعار الوقود & Kenaikan Harga BBM \\
\hline تخفيض الدعم & Pengurangan Subsidi \\
\hline وزير الطاقة والموارد التعدينيـة & Menteri Energy dan Sumber Daya Mineral \\
\hline 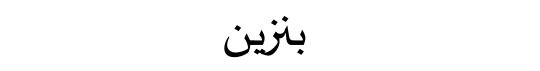 & Bensin \\
\hline ديزل / سولار & Solar \\
\hline متر مكعب & Meter Kubik \\
\hline
\end{tabular}
kemudian menjadi satu-satunya nama pesohor yg ditempel di dinding."

المثال الثاني: الكلمات المعاصرة 19 
Farid Permana: Al Lughah al 'Arabiyyah al Fuṣhā al Mu'ạṣarah wa Ta' limuhā

\begin{tabular}{|c|c|}
\hline تطبيق الأسعار الجـلديلدة & Pemberlakuan Harga Baru \\
\hline محطات البتزين / الوقود & SPBU \\
\hline طوابير طويلة & Antrean Panjang \\
\hline دعم & Subsidi \\
\hline تقليل الدعم عن الوقود & Pengurangan Subsidi BBM \\
\hline ميزانية البلاد & APBN / Anggaran Negara \\
\hline
\end{tabular}

\section{التحديات للغة العربية الفصحى المعاصرة·r ra}

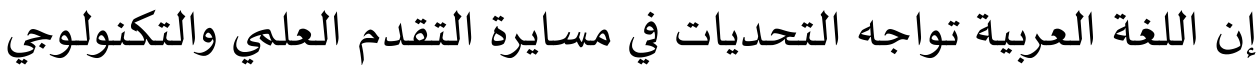

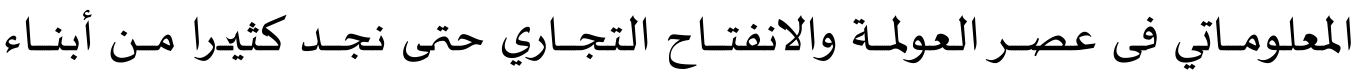
المسلمين هربوا منها، ويظنون أن هذه اللغة ليس لها مستقبل باهر ـ وبعضهم

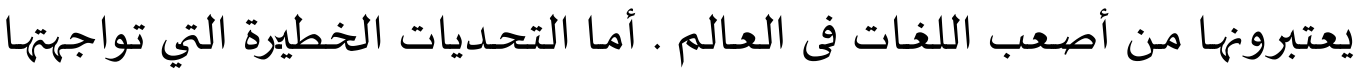

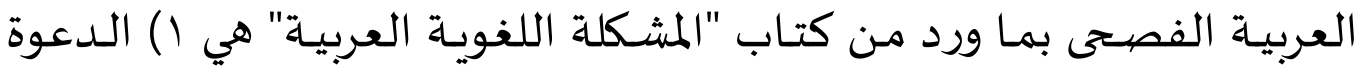

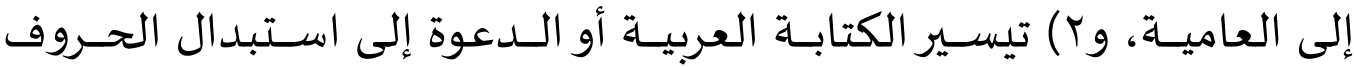

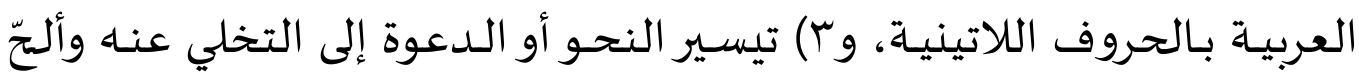
(pressing) r لا يبحث الباحث عنها في هذه المقالة إلا لوصفها وصفاً بسيطا حتى يدركها القارئ عامةً 
التعلـيم باللغــة الأجنبيـة على رأي أسـاسـي وهــو أن اللغــة العربيـة الفصيـيحة

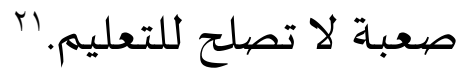

\section{و. تعليم اللغة الفصسى المعاصرة واكتسابها في جامعة لعلوم القرآن بآمونتاي}

كانـت جامعـة علـوم القـرآن بآمونتـاي كليمانتـان الجنوبيـة مـن إحسـى

الجامعــات التهي تســى إلى إعـــاد مرشــي المعلمــين للغـــة العربيــة في

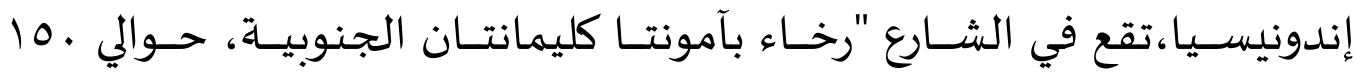

كيلومتر من مدينة بانجارماسين. يتعلم فيها الطلبة علوم القرآن و علوم التربية

و اللغــة العربيـة وتعليمهـا، اتجهـت إلى تأهيـل المعلمــين اللغــة العربيـة لأبنـاء

الإندونيسيين الذين هم غير ناطقين بها، وبخاصية لتعليم اللغـة العربية هنـاك

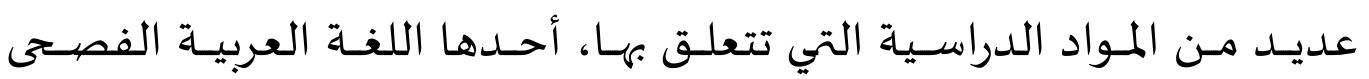

المعاصرة.

كان تعليم اللغـة العربيـة الفصدح المعاصـرة في هـذه الجامعـة تقع داخل الفصل أكثر والأهداف من تعليمها هي:

1. لترقية كفاءت الطلبة في فهم اللغة العربية الفصحى المعاصرة وتطبيقها نطقاً و كتاباً.

2. تمكين الطلبة من الاتصال بمصادر الثقافة العربية وقراءة كتاباتها وفهم نصيوصها نحو الكتب التراثية والكتب أو المجلات المعاصرة وغير

ذلك.

3. لترقية الكفاءت التعليمية لمرشح المعلمين أو الطلبة في تنفيذ تدريس اللغة العربية مع تطبيق المداخل و الطرائق و الأسـاليب المناسبة لمربة المبلية

$$
\text { فياء.r }
$$

ץ انظر هذه التحديات إلى الفيصل، سمر روحي، المشكلة اللغوية العربية (لبنان: جروس برس، بو99) 
والطريقة المستخدمة لتعليم اللغـة العربية الفصيحى المعاصرة هي طريقة

القواعـد والترجمـة أي وهي التي تبـدأ بتعلـيم القواعـد وشـرحها شـرحا طـويلا

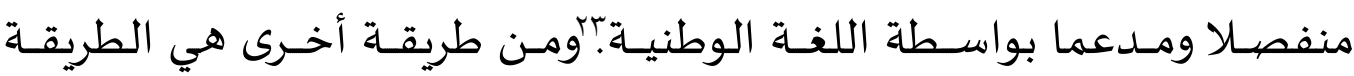
القـراءة، أسـتخدمت هـذه الطريقـة لأجـل التحليـل للكتب أو المجـلات المعاصـرة. ومن اسـتراتجيات التي جـرت عند تعليم اللغـة المعاصـرة أقدمها إثراء المفردات الجديـدة المعاصـرة مـع نطقهـا نطقـاً سـليماً حتى يسـمعها الطلبـة ويكررونهـا بصـوت عـال، ثم يـأتي المحاضـر بسـؤال عـن معناهها و كتابتهـا على السـبورة، والأمر بوضعها في جملة مفيدة حتى يفهم الطلاب معنى من المفردات المعاصرة المعطية. وهذه العملية تجري كل يوم في الفصل. وأمـا المحتـوى لتعليم اللغـة العربيـة الفصـى المعاصـرة في جامعـة لعلـوم القـرآن بآمونتـاي هــو مجموعــة المواقـف التعليميــة ذات المضــمون اللغــوي والثقافي والاتصالي المقدمة للطلاب. قام المحاضـر بتقويم تعليم اللغـة العربية الفصحى المعاصرة لمعرفة مدى نجـاح تعليمهـا. بحيـث أن هـذا التقـويم تـم عقـــه بالإمتحـان لنصـف الدراسـي

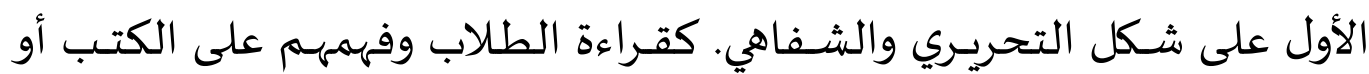
النصوص المعاصرة المهيأ. وفي مجـال اكتسـاب العربيـة الفصهى المعاصـرة، قامت الجامعـة بتطوير البيئـة اللغويـاة خـارج الفصـل نحـو بنـاء المنـاطق اللازمـاة على الكلام بالعربيـة، وعـرض المعلومـات الأكاديميكيـة المكتوبـة باللغــة العربيـة و إحضــار المشـرف

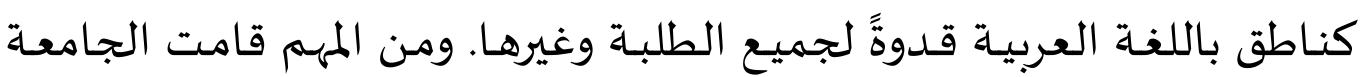

فريد فرمانا،"إعداد فيديو تعليمي لكتاب "طرائق تدريس اللغة العربية للأستاذ أحمد فؤاد أفندي (بحث

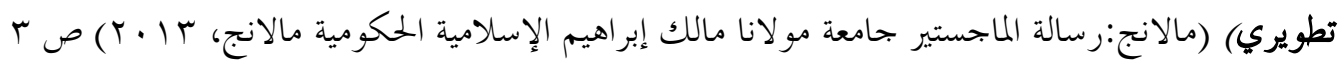

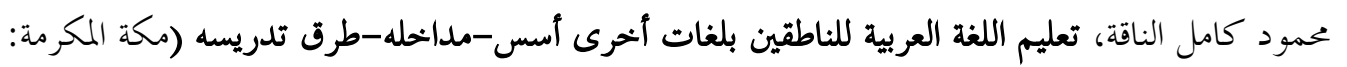

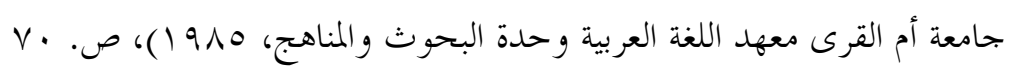


بتتنميـة نفـوس الطلبـة نحـو تشـيعهم على ممارسـة الكلام العربيـة الفصسى و كثرة مطالعة الكتب أو المجلات أو الجريدة العربية المعصرة.

\section{ز. المشكلات الموجهة وحلها في تعليم اللغة العربية الفصدى المعاصرة}

من المشكلات التي وجهها المحاضر في تعليم اللغة العربية الفصهى

$$
\text { المعاصرة هي: }
$$

1. تنوعت خلفياة دراسة الطلاب، منهم من تخرج من المعهد وتعلم اللغة العربية من قبل، ومنهم من تخرج من المدرساة الثانوية الإسلامياة وتعلم وعرف قليلا من اللغة العربية، ومنهم دون ذلك. وهذا يصعب

$$
\text { المحاضر في القاء محاضرته. }
$$

2. قلة المراجع من الكتب والمجلات العربية الفصجي المعاصرة. 3. ومن بعض المشكلات تصدرر من نفس الطلاب داخلياً وخارجياً نحو قلة الهمة والتشجيعة والقدوة المتبع وغير ذلك. وعلى هذه المشكلات كلها، فيمكن للباحث من حلها فيما يلي: 1. إقامة بتقسيم الفصل إلى الفصول نحو فصل الألف و الباء والجيم، وأجلسهم في كل فصل على قدر كفاءتهم العربية، وهذه طبعاً بالنظر إنساء إلى جانب من جوانب أخرى مثل عدد المحاضر والوسائط والمادية المتاحة. 2. إحضيار كتب العربية المعاصرة أو المجلات و الجرائد من خلال التعاون بالمؤسسات التعليمية الأخرى. 3. محتاج بالضرورة إلى المحاضر الذي عنده قدرة على دافعية الطلاب.

\section{الخلاصة}

الفصحى المعاصر أو العربية المعيارية المعاصرة هي اللغة التي تكتب بها الصحف اليومية والكتب والتقارير والخطابات، وتلقى بها الأحاديث في أجهزة 
الاعلام، ويتحدث بها المسئولون في لقاءاتهم العامة، والخطباء في خطبهم، وتدار بها الاجتماعات الرسمية، وتؤدي بها بعض المسرحيات وغير ذلك من مواقف تستخدم فهها الفصحى لغة للفهم والإفهام، وهي لغة المنطوقة و المكتوبة

انطلاقا بما ذكرناه فإن مستقبل اللغة العربية في العالم بوجه عام، وفي

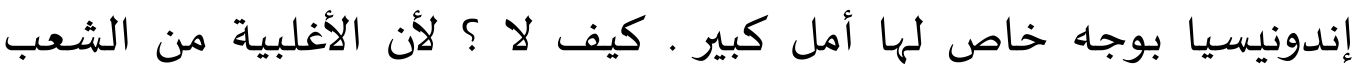
الإندونيسي يعتنقون الدين الإسلامي، واللغة العربية لها علاقة وثيقة بكتابها المقدس وأداء مشاعره الدينية، فضلا عن ذلك فإن عددا غير قليل من الإنافئ

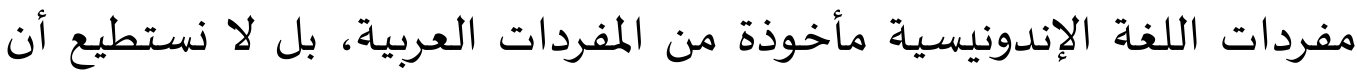
نتخلص منها إذا تحدثنا ولو مدة يسيرة وبناء على هذا فرأى الباحث هنا أن التعليم الصحيح للغة العربية لابد أن يهتم بالنقاط الآتية :- تصحيح الهدف من دراسة اللغة العربية، الإعداد الكامل للمواد اللغوية، وجود المدرسين المؤهلين بالتدريس، وطرق التدريس المناسبة للمتعلمين، و استخدام الوسائل التعليمية الحديثة، وعقد دورات تدريبية للمدرسين. والله أعلم.

\section{المراجع}

يعقوب، إميل بديع, موسوعة علوم اللغة العربية، بيروت: دار الكتب العلمياة، r... T

جرجى زيدان، تاريخ آداب اللغة العربية بيروت: دار المكتبة الحياة

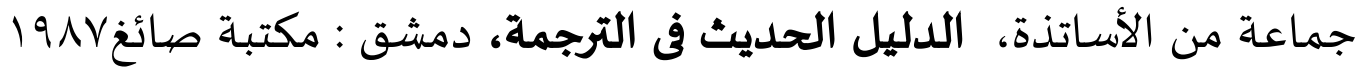


رشدي أحمد طعيمة، تعليم العربية لغير الناطقين بها ـ الرباط : المنظمة

$$
\text { الإسلامية للتربية والعلوم والثقافة } 1919
$$

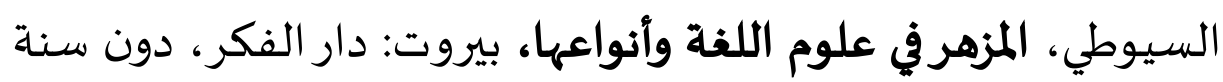
عبد الجني، فقه اللغة وعلم اللغة نصوص الدراسات، القهرة: دار

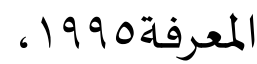

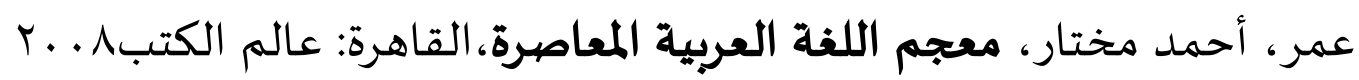

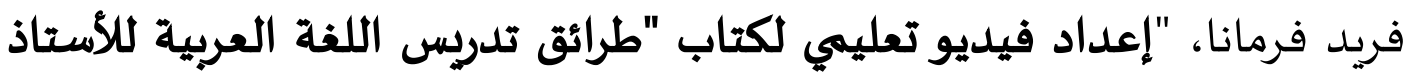

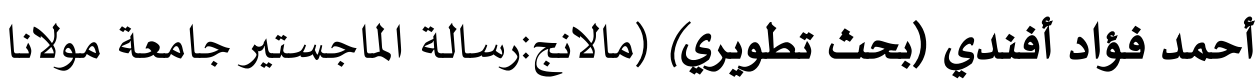

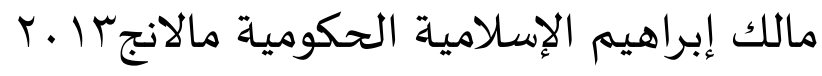

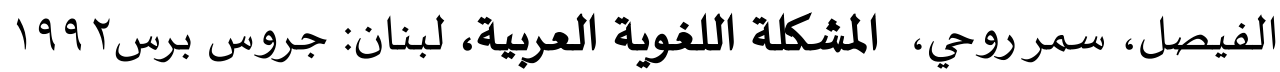

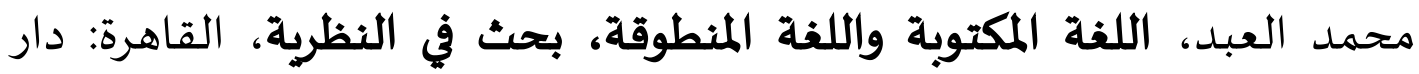

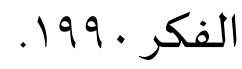

محمد عبد الفتاح العمراوي، تطور اللغة العربية المعاصرة بين ضوابط القدماء

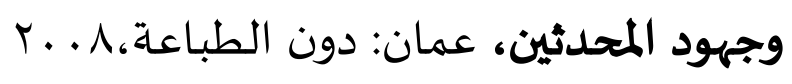

محمود كامل الناقة، تعليم اللغة العربية للناطقين بلغات دون الطباعة أخرى أسس-

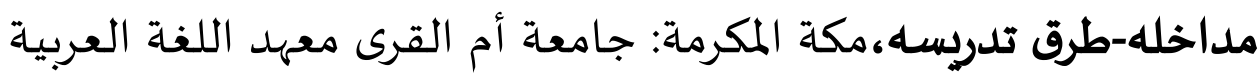

$$
\text { وحدة البحوث والمناهج } 1910
$$

الواحد، السيد على عبد . دون تاريخ ـ المعلم فى اللغة العربية، القاهرة :

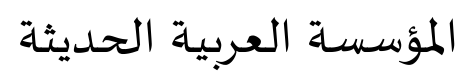

